\title{
The Use of Neuronavigation and Intraoperative Imaging in Spinal Stabilization Surgery
}

\author{
Ozkan TEHLI ${ }^{1}$, Ferhat HARMAN²${ }^{2}$, Caglar TEMIZ ${ }^{1}$, Yunus KACAR ${ }^{1}$, Burak KAZANCI ${ }^{3}$, Mehmet DANEYEMEZ $^{1}$, \\ Ilker SOLMAZ1', Cahit KURAL ${ }^{1}$ \\ ${ }^{1}$ Gulhane Military Medical Academy, Department of Neurosurgery, Ankara, Turkey \\ ${ }^{2}$ Near East University, Department of Neurosurgery, Lefkosa, Turkish Republic of Northern Cyprus \\ ${ }^{3}$ Ufuk University, School of Medicine, Department of Neurosurgery, Ankara, Turkey
}

\section{ABSTRACT}

AIM: Misplacement of pedicle screw is the serious complication of spinal surgeries. Intraoperative imaging techniques and navigation systems are currently in use for the prevention of this complication. The aim of this study was to document the results of our experience with the navigation and intraoperative imaging technique and to share our experience with our colleagues.

MATERIAL and METHODS: Between 2011 and 2014, one hundred and two patients underwent instrumented spinal surgery while using intraoperative computed tomography (iCT) and a navigation system. All patients had a CT scan performed no more than three days postoperatively to confirm adequate placement of the screws. The accuracy of pedicle screw placement was assessed by postoperative CT scan. Pedicle violations were graded according to an established classification system.

RESULTS: In the 36-month period, a total of 610 screws in 102 patients were evaluated. Stabilization surgery was performed in the lumbosacral region in $51(50 \%)$ patients, lumbar region in $35(34.31 \%)$ patients, cervical region in 5 (4.9\%) patients, thoracolumbar region in $7(6.86 \%)$ patients and thoracic region in 4 (3.92\%) patients. Of the 610 screws, $396(64.91 \%)$ were placed in lumbar, 66 $(10.81 \%)$ in thoracic, $106(17.37 \%)$ in sacral and $42(6.8 \%)$ in cervical vertebrae. Of the 610 screws, 599 screws (98.18\%) were placed without a breach. Grade 1 breaches occurred in 8 screws (1.31\%), Grade 2 breaches occurred in 2 screws (0.32\%), and Grade 3 breaches in 1 screw $(0.16 \%)$. No dural defect or neurological deficit occurred after the surgeries.

CONCLUSION: The use of an iCT scan associated with a navigation system increases the accuracy of pedicle screw placement. This system protects the surgical team from fluoroscopic radiation exposure and the patient from the complications of screw misplacement and repeated surgeries.

KEYWORDS: Intraoperative imaging, Spinal surgery, Navigation, Pedicle screw

\section{INTRODUCTION}

$\mathrm{P}$ edicle screw insertion is always a challenge for spine surgeons because of its association with the risk of morbidity. Improper screw placement may result in nerve and dural injuries. This causes persistent pain, neurological deficits, cerebrospinal fluid (CSF) fistula, infections and, increased costs for patients $(2,9,24)$. Together with the use of fluoroscopy, the misplaced screw rate has decreased but still reported as $12 \%$ to $21 \%(11,22)$.
During the last two decades, navigation techniques have become increasingly important in spinal surgery $(3,4,10,21)$. The use of navigation based on preoperative computed tomography (CT) scan imaging has reduced the number of misplaced screws, but has not fully eliminated them $(5,11$, 26). More recently, the use of intraoperative CT (iCT) with a neuronavigation system has raised the accuracy of pedicle screw placement $(12,15,28)$. 
Tehli O. et al: Intraoperative Imaging in Spinal Surgery

In this study, we tried to show our experience with iCT in association with the navigation system and compared our results with the previous studies. The study design was retrospective.

\section{- MATERIAL and METHODS}

Between January 2011 and March 2014, 102 patients underwent transpedicular screw instrumentation of the cervical, thoracic, thoracolumbar, lumbar and lumbosacral regions (Table I). Patients included in this study underwent surgery for degenerative conditions, traumas, tumors, and osteoporotic fractures. All patients had given their informed consent to have an iCT scan performed. All surgical procedures were performed by experienced spine surgeons. iCT $(\mathrm{O}$-arm $\AA$, Medtronic Inc; Louisville, CO, USA) which combines with the navigation systems (StealthStation $\AA$, Medtronic Inc, Louisville, CO, USA) was used for this study. Medical records and imaging were retrospectively reviewed to document age, sex, diagnosis, levels of fixation, intraoperative and postoperative complications, and screw malposition.

All patients were positioned prone on a Jackson radiolucent table permitting movement to a stored scanning position (Figure 1). It was possible to back the operating position any time during surgery. A skin incision was made after sterile draping of the operating field and the iCT, and a reference frame was clamped to an exposed spinous process (Figure 2). The correct surgical intervention according to the pathology in each case was performed before the instrumentation. A three-dimensional (3D) scan was obtained at the beginning of the instrumentation period. After this, the images were reconstructed automatically, and the $3 \mathrm{D}$ reconstruction appeared on the screen of the iCT. This 3D images obtained were automatically transferred to the navigation system. With the navigated instruments and under image guidance, each pedicle was probed, tapped, and filled in with a screw. The

Table I: Summary of the Preoperative Demographics of Patients Undergoing Pedicle Screw Placement with Intraoperative Computed Tomography (iCT) Based Navigation

\begin{tabular}{lc}
\hline Characteristic & Value \\
\hline No. of patients & 102 \\
\hline No. of screws & 610 \\
\hline Sex . Male & \\
- Female & $59(57.84 \%)$ \\
\hline Age (years) & $43(42.15 \%)$ \\
- Mean & \\
- range & 41.2 \\
\hline
\end{tabular}

\section{Preop. diagnosis}

- degenerative conditions

$65(63.72 \%)$

- traumas

$32(31.37 \%)$

- tumors

$2(1.96 \%)$

- osteoporotic fractures validity of the system was intermittently checked by placing a navigated probe on an exact anatomic landmark. During the procedure, the system alerted when accuracy was not to within $1 \mathrm{~mm}$, and this indicated that correction was needed.

When all screws were in place, their position was evaluated and confirmed with a new iCT scan. If screw revision was required, another iCT scan was obtained in order to perform correction of a misplaced screw. All patients had a CT scan performed no more than three days postoperatively to confirm adequate placement of the screws. The pedicle breach rate was scored from 0 to 3 by 2 blinded neurosurgeons as described by Mirza et al. A breach of $<2 \mathrm{~mm}$ was considered Grade 1, a breach of 2-4 $\mathrm{mm}$ was considered Grade 2, and a breach of $>4 \mathrm{~mm}$ was considered Grade 3 (14). Stability was documented on an upright $\mathrm{x}$-ray without the orthosis, performed during follow-up to verify maintenance of alignment.

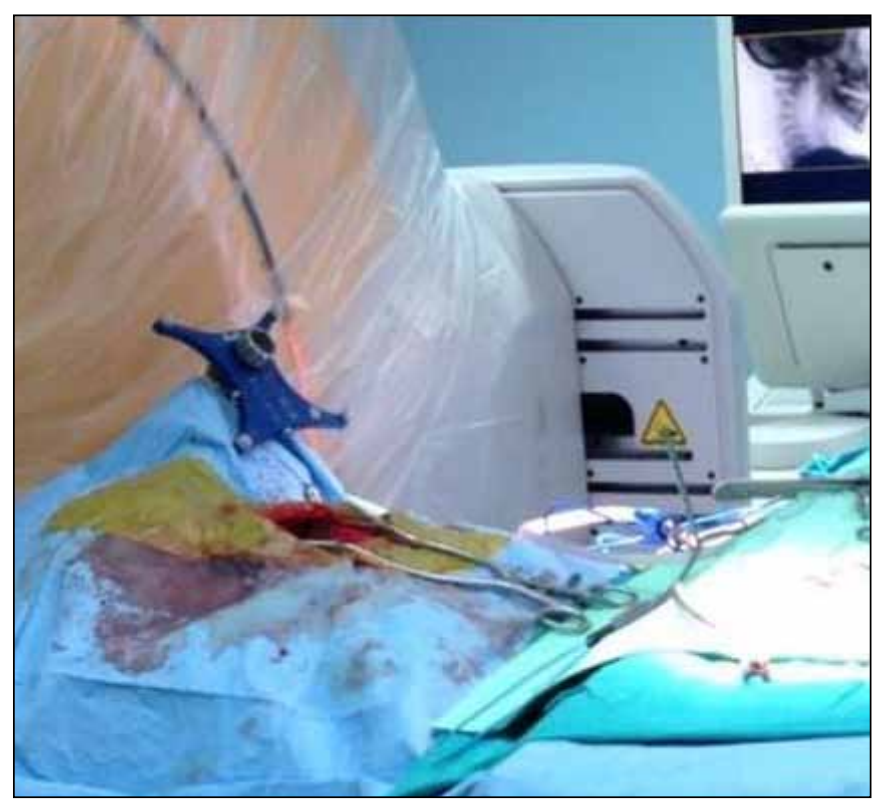

Figure 1: Position of the patient and O-Arm at the end of cervical spine surgery.

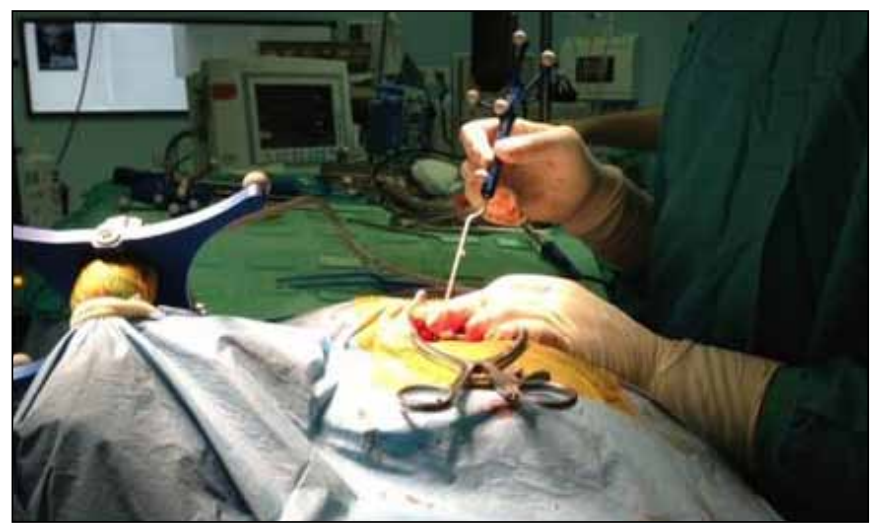

Figure 2: The reference frame is clamped to an exposed spinous process for the setup of the navigation system and the navigation probe is used to verify the accuracy of the images. 


\section{RESULTS}

Table I summarizes the preoperative baseline characteristics of the patients undergoing screw placement with the iCTbased navigation (iCTN) system. The mean patient age was 41.2 years (range 9 years to 70 years). There were 59 men and 43 women. The most common diagnoses were degenerative conditions (spinal stenosis, disc degeneration and herniation, degenerative spondylolisthesis), comprising $63.72 \%$ of patients. Other diagnoses were traumas $(31.37 \%)$, tumors (1.96\%), and osteoporotic fractures (2.94\%). During the 36-month period, there were 610 screws (Figure 3) placed in 102 patients with the use of the iCTN system. In the 102 patients, 39 (38.2\%) underwent a 1-level, 35 (34.31\%) underwent 2-level, 19 (18.62\%) underwent a 3-level, 5 (4.9\%) underwent 4-level, 4 (3.92\%) underwent 5-level surgery.

\section{The distribution of the screws}

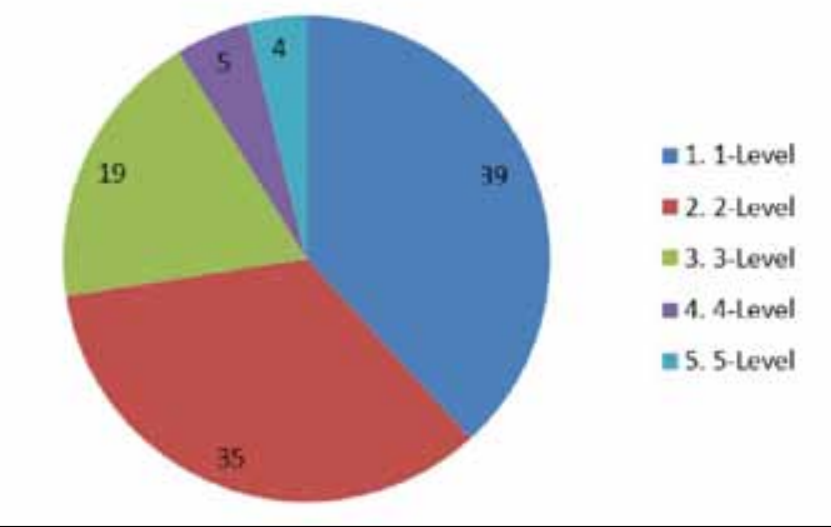

Figure 3: The distribution of the screws based on the vertebrae.

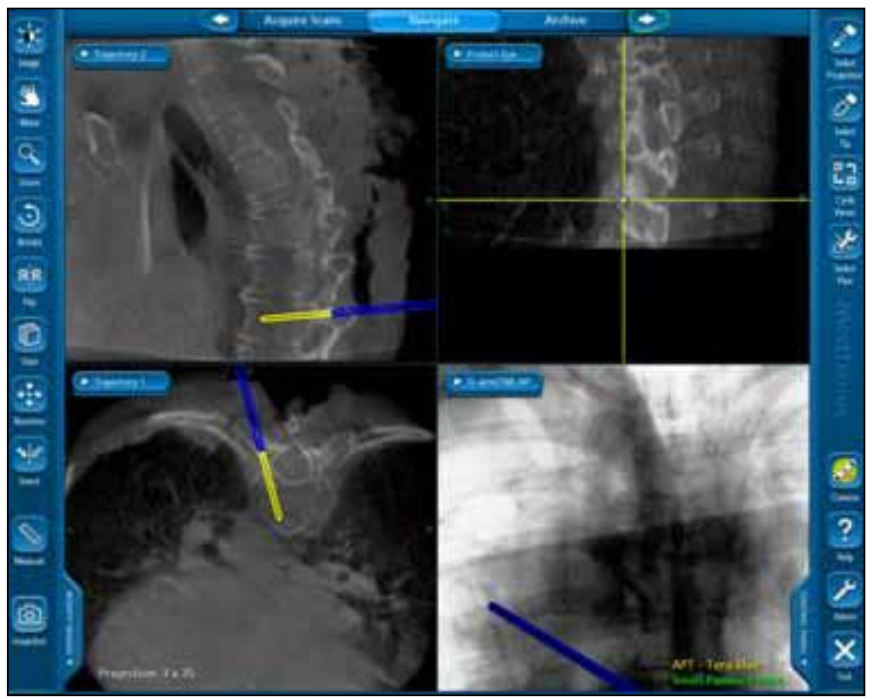

Figure 5: Screw placement sites in sagittal, coronal and axial planes are verified using iCT images in thoracic spine.
Pedicle screw placement was performed in the cervical region, thoracic region, thoracolumbar region, lumbar region, and lumbosacral region (Figures 4-6). Of the 610 pedicle screws, $599(98.19 \%)$ screws were placed without a breach and 11 (1.8\%) breaches occurred. 10 breaches were lateral $(1.63 \%)$, 1 breach was medial (0.16\%). Grade 1 breaches acoounted for $1.31 \%$, Grade 2 breaches $0.32 \%$, and grade 3 breaches $0.16 \%$. No dural defect or neurological deficit occurred after the surgeries. The mean follow-up period was 8 months, and ranged between 3 and 18 months.

\section{DISCUSSION}

Since being popularised by Roy-Camille, pedicle screws have become one of the most favoured methods of posterior spinal fixation (16). Biomechanical studies have reflected

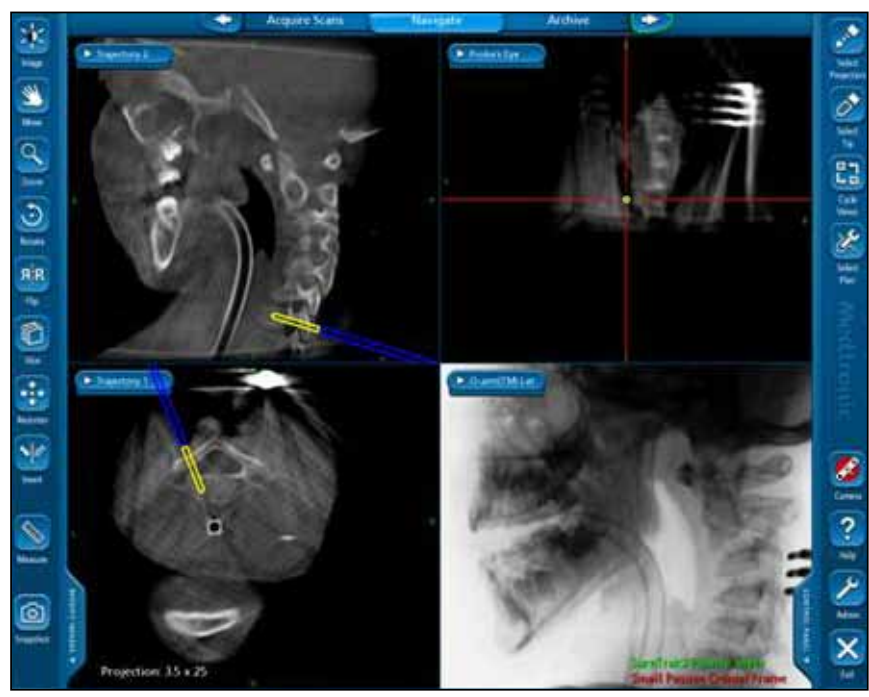

Figure 4: Determination of the screw placement sites in the cervical spine using real-time iCT images.

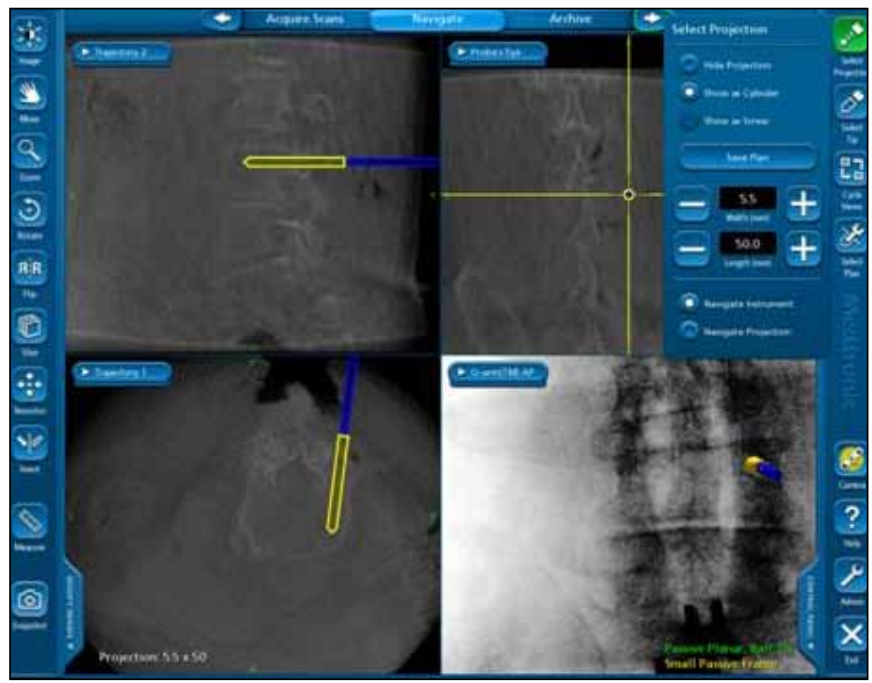

Figure 6: Placement of the pedicle screws in lumbar spine using iCT images. 
Tehli O. et al: Intraoperative Imaging in Spinal Surgery

that increased rigidity and stiffness of construction have been provided by pedicle screws in comparison to other posterior fixation techniques (6). It is a technically demanding procedure and studies have shown between $12 \%-21 \%$ screw malposition even with the aid of fluoroscopy $(11,22)$.

Currently, modern spinal navigation systems include 3D fluoroscopy -based navigation, preoperative CT-based navigation, and computer-assisted navigation, which are all in common usage (9). iCTN system is one of the latest navigation tools which guides the surgeons for various surgical interventions, including proper pedicle screw placement in spinal surgery.

Tian et al. reviewed the 43 papers including cadaveric and clinical models, and they carried out meta-analyses of comparative studies. They showed that navigation provided higher accuracy in the placement of pedicle screws compared with conventional methods. They suggest that the superiority of the navigation system was obvious when applied to an abnormal spine structure. A significant difference in pedicle screw placement accuracy was not found between the three major navigation systems (CT-based navigation system, two-dimensional (2D) fluoroscopy-based navigation system, and 3D fluoroscopy-based navigation system) in their study (25). However, in their reviews, all of the CT-based navigation systems used preoperative CT images and not the iCT images for pedicle screw insertion. So, the iCTN system was not compared among preoperative CT, 2D and 3D fluoroscopybased navigation systems. In a recent study, the iCTN system provided better results than the use of preoperative CT-based navigation system (4). Shin et al. evaluated and compared the accuracy and safety of the pedicle screw placement between a C-arm and the iCTN system in a prospective randomized study. They suggested that the iCTN system was more accurate and safer than the conventional C-arm for pedicle screw placement (22). Oertel et al. evaluated the clinical and methodological precision of the iCTN system (15). Pedicle perforations were recorded in $3.2 \%$ of pedicle screws in their study. They suggested that the use of iCTN system had shown the highest accuracy compared with traditional methods. An international, multicenter, prospective study evaluated the accuracy of pedicle screw placement with the use of an iCTN system (28). Misplacement of the screw occurred in $2.5 \%$ of the screws, and only $1.8 \%$ of the screws needed to be revised intraoperatively. The study showed that the use of the iCTN system increased the accuracy of pedicle screw placement. In another study, Zausinger et al. evaluated prospectively the clinical outcome of navigated stabilization procedures in spinal surgery with iCT. They suggested that the ICTN system provides high accuracy of screw placement (29). Otherwise, a cadaveric study found similar breach rates between the iCTN system and C-arm for the placement of pedicle screws (22). According to our records, with 610 screws inserted in a 36-month period at different spine levels, 599 screws were placed without a breach. Grade 1 breaches occurred in 8 screws (1.31\%), Grade 2 breaches in 2 screws $(0.32 \%)$, and Grade 3 breach in 1 screw (0.16\%). There was no revision surgery performed for screw placement. No dural defect or neurological deficit occurred after surgery. We suggest that the iCTN system is safe and it increases the accuracy of pedicle screw placement, which is compatible with other previous studies $(4,5,8,14,17,18,21,26,28)$.

The instrumentation time for the iCTN system is shorter than conventional C-arm aided pedicle screw placement, but it needs a longer setup time (22). Zausinger et al. evaluated the workflow of iCTN system in 94 patients for spinal instrumentation and they showed that imaging times were comparable with fluoroscopy (29). Scheufler et al. assessed the time required for placement of 826 thoracolumbar pedicle screws placement with the iCTN system, and suggested that an iCTN system used with automated referencing was time-efficient (19). In a recent retrospective study, Ling et al. evaluated the operative time of patients in which an iCTN system was used and compared it with a matched control group in which fluoroscopy was used. The mean operative time was 5.25 hours for iCTN patients and 4.75 hours for a matched control group of fluoroscopy patients. The difference in the mean operative time between the two groups was not statistically significant in their study (13). We did not evaluate the workflow in this study, but we think that it was needed for the duration of the operation which can then be reduced hence with experience.

One of the main advantages of the iCTN system among the preoperative-CT based navigation systems is that ICT allows images to be taken when the patient is positioned prone on the operating table. This reduces positioning variability and, therefore navigation error $(8,12,25)$. Furthermore, the iCTN system is a useful tool for an accurate evaluation of a pedicle breach in intraoperative settings $(12,17)$. Thus the iCTN system allows the surgeon perform real-time revision during surgery. Santos et al. evaluated the accuracy of iCT images in determining pedicle screw position using open dissection as the gold standard in 9 cadavers. They found that the iCT images accurately detected significant pedicle screw violations in the thoracic and lumbar spine, but were less accurate for the cervical spine (17). In our series, there was no difference between the cervical, thoracic and lumbar regions based on the accuracy of pedicle screw fixation. The navigation system provided us a safe trajectory for screw placement during the surgery.

Another advantage of the iCTN system is that it might be more effective for demanding levels in the thoracic and cervical spine $(19,27)$. In a prospective study, Dinesh et al. evaluated the clinical feasibility and accuracy of the iCTN system for thoracic pedicle screw instrumentation (5). They detected 7 (2.7\%) pedicle violations in 261 thoracic pedicle screws (T1T12) and only four of the screws (1.5\%) that breached the pedicle wall by more than $2 \mathrm{~mm}$ were immediately revised before wound closure. They suggested that the iCTN system is safer and has a high accuracy rate $(97.3 \%)$ for thoracic pedicle screw placements. Ughwanogho et al. compared the accuracy and safety of thoracic pedicle screw placement in the deformed spine using the iCTN system and a freehand technique with $\mathrm{C}$-arm confirmation (27). They showed that the iCTN system significantly enhanced accuracy and safe placement of thoracic pedicle screws compared with the freehand technique with $\mathrm{C}$-arm confirmation. In a recent 
retrospective study, Ling et al. reported $95.3 \%$ accuracy with the iCTN system for thoraco-lumbar pedicle screw insertion. They found the less than $2 \mathrm{~mm}$ pedicle violation rate to be $3.4 \%$ and the $2-4 \mathrm{~mm}$ pedicle violation rate to be $1.3 \%$ (13). In a recent study, Tow et al. assessed the accuracy of the iCTN system for pedicle screw insertion in lumbar degenerative spondylolisthesis, and compared it with a freehand pedicle screw insertion technique in a matched population (26). The rate of perforation of pedicles was not significantly different between the two groups. Insertion of lumbar pedicle screws is more familiar and easier for the surgeons than thoracic pedicles $(12,20)$. This may be a reason for similar results between the iCTN and freehand techniques in the lower lumbar spine. In our series, we did not compare the screw positions based on the region of vertebral column.

iCT was also helpful in order to overcome various problems we had previously experienced with a C-arm. iCT scan has better image quality than the 3D fluoroscopy system. In additon, iCT viewed a larger field than 3D fluoroscopy. In overweight patients, satisfactory images with fluoroscopy can be a challenge while this is not the case for the iCT scan (8). In our study, even with the overweight patients we were more satisfied with the image quality of the $\mathrm{ICT}$ scan than fluoroscopy.

With the use of iCT and fluoroscopy, radiation exposure is a significant concern for both the surgical team and the patient. Abdullah et al. determined the radiation exposure to the spinal surgeon with the use of an iCTN system, and they suggested that radiation exposure was minimal to the surgical team during routine use of the iCTN system (1). In the cadaveric study of Tabaree et al., it was shown that the iCT exposed the surgeon to less radiation, but the cadaver received higher doses (23). Van de Kelft et al. did not recommend an additional iCT scan if the surgeon's perception of a correct pedicle screw trajectory was justified. In effect, this reduces radiation exposure for the patient (28). During the iCT scan, the surgical team has the possibility of standing behind radiation-shielded walls, and when compared with fluoroscopy, there is a significant reduction in the team's exposure to radiation.

The main disadvantage of the iCTN system is its high-cost compared with previous conservative methods. There is ongoing debate regarding cost-effectiveness of the iCTN system (7). Multidisciplinary use increases utilization of the system and thus may improve cost-efficiency (29). In our opinion, the decrease in the complication rates of spinal surgery, with the use of iCTN system may amortise high costs in the long run. Further studies are needed to determine the cost-effectiveness of iCTN system.

\section{CONCLUSION}

An intraoperative imaging system and navigation provide realtime, intra-operative imaging of a patient's surgical anatomy with high quality radiological images and a large field-ofview in both two and three dimensions. This system is also a promising tool to improve the safety of spinal stabilization and screw placement. Using this technology, spinal surgeons are able to perform less invasive procedures and confirm the precision of advanced surgical procedures before the patient leaves the operating room. Further studies with more patients would clarify the usefulness of the iCTN system in spinal surgery.

\section{REFERENCES}

1. Abdullah KG, Bishop FS, Lubelski D, Steinmetz MP, Benzel EC, Mroz TE: Radiation exposure to the spine surgeon in lumbar and thoracolumbar fusions with the use of an intraoperative computed tomographic 3-dimensional imaging system. Spine 37:E1074-1078, 2012

2. Abul-Kasim K, Ohlin A, Strömbeck A, Maly P, Sundgren PC: Radiological and clinical outcome of screw placement in adolescent idiopathic scoliosis: Evaluation with low-dose computed tomography. Eur Spine J 19:96-104, 2010

3. Carl AL, Khanuja HS, Gatto CA, Matsumoto M, vomLehn J, Schenck J, Rohling K, Lorensen W, Vosburgh K: In vivo pedicle screw placement: Image-guided virtual vision. J Spinal Disord 13:225-229, 2000

4. Costa F, Cardia A, Ortolina A, Fabio G, Zerbi A, Fornari M: Spinal navigation: Standard preoperative versus intraoperative computed tomography data set acquisition for computerguidance system: Radiological and clinical study in 100 consecutive patients. Spine 36:2094-2098, 2011

5. Dinesh SK, Tiruchelvarayan $\mathrm{R}, \mathrm{Ng}$ I: A prospective study on the use of intraoperative computed tomography (iCT) for image-guided placement of thoracic pedicle screws. $\mathrm{Br} \mathrm{J}$ Neurosurgery 26:838-844, 2012

6. Ferguson RL, Tencer AF, Woodard P, Allen BL Jr: Biomechanical comparisons of spinal fracture models and the stabilizing effects of posterior instrumentations. Spine 13:453-460, 1988

7. Hecht AC, Koehler SM, Laudone JC, Jenkins A, Qureshi S: Is intraoperative CT of posterior cervical spine instrumentation cost-effective and does it reduce complications? Clin Orthop Relat Res 469:1035-1041, 2011

8. Houten JK, Nasser R, Baxi N: Clinical assessment of percutaneous lumbar pedicle screw placement using the O-arm multidimensional surgical imaging system. Neurosurgery 70 : 990-995, 2012

9. Izci Y, Taskaynatan MA: Management of lower back pain in young Turkish recruits. Mil Med 169(10):824-828, 2004

10. Laine T, Lund T, Ylikoski M, Lohikoski J, Schlenzka D: Accuracy of pedicle screw insertion with and without computer assistance: A randomised controlled clinical study in 100 consecutive patients. Eur Spine J 9:235-240, 2000

11. Laine T, Mäkitalo K, Schlenzka D, Tallroth K, Poussa M, Alho A: Accuracy of pedicle screw insertion: A prospective CT study in 30 low back patients. Eur Spine J 6:402-405, 1997

12. Larson AN, Santos ER, Polly DW Jr, Ledonio CG, Sembrano $\mathrm{JN}$, Mielke $\mathrm{CH}$, Guidera KJ: Pediatric pedicle screw placement using intraoperative computed tomography and 3-dimensional image-guided navigation. Spine 37:E188-194, 2012

13. Ling JM, Dinesh SK, Pang BC, Chen MW, Lim HL, Louange DT, Yu CS, Wang CM: Routine spinal navigation for thoracolumbar pedicle screw insertion using the O-arm threedimensional imaging system improves placement accuracy. J Clin Neurosci 21(3):493-498, 2014 
Tehli O. et al: Intraoperative Imaging in Spinal Surgery

14. Mirza SK, Wiggins GC, Kuntz C 4th, York JE, Bellabarba C, Knonodi MA, Chapman JR, Shaffrey Cl: Accuracy of thoracic vertebral body screw placement using standard fluoroscopy, fluoroscopic image guidance, and computed tomographic image guidance: A cadaver study. Spine (Phila Pa 1976) 28(4):402-413, 2003

15. Oertel MF, Hobart J, Stein M, Schreiber V, Scharbrodt W: Clinical and methodological precision of spinal navigation assisted by $3 \mathrm{D}$ intraoperative $\mathrm{O}$-arm radiographic imaging. $\mathrm{J}$ Neurosurg Spine 14:532-536, 2011

16. Roy-Camille R, Saillant G, Mazel C: Internal fixation of the lumbar spine with pedicle screw plating. Clin Orthop Relat Res 203:7-17, 1986

17. Santos ER, Ledonio CG, Castro CA, Truong WH, Sembrano $\mathrm{JN}$ : The accuracy of intraoperative O-arm images for the assessment of pedicle screw postion. Spine 37:E119-125, 2012

18. Scheufler KM, Franke J, Eckardt A, Dohmen H: Accuracy of image-guided pedicle screw placement using intraoperative computed tomography-based navigation with automated referencing. Part II: thoracolumbar spine. Neurosurgery 69:1307-1316, 2011

19. Scheufler KM, Franke J, Eckardt A, Dohmen H: Accuracy of image-guided pedicle screw placement using intraoperative computed tomography-based navigation with automated referencing, part I: Cervicothoracic spine. Neurosurgery 69:782-795, 2011

20. Schizas C, Theumann N, Kosmopoulos V: Inserting pedicle screws in the upper thoracic spine without the use of fluoroscopy or image guidance. Is it safe? Eur Spine J 16:625629, 2007

21. Schwarzenbach $O$, Berlemann $U$, Jost $B$, Visarius $H$, Arm E, Langlotz F, Nolte LP, Ozdoba C: Accuracy of computerassisted pedicle screw placement. An in vivo computed tomography analysis. Spine 22:452-458, 1997
22. Shin MH, Hur JW, Ryu KS, Park CK: Prospective comparison study between the fluoroscopy guided and navigation coupled with $\mathrm{O}$-arm ${ }^{\circledR}$ guided pedicle screw placement in the thoracic and lumbosacral spines. J Spinal Disord Tech 28(6): E347-E351, 2015

23. Tabaraee E, Gibson AG, Karahalios DG, Potts EA, Mobasser JP, Burch S: Intraoperative cone beam-computed tomography with navigation (O-ARM) versus conventional fluoroscopy (C-ARM): A cadaveric study comparing accuracy, efficiency, and safety for spinal instrumentation. Spine 38:1953-1958, 2013

24. Taskaynatan MA, Izci Y, Ozgul A, Hazneci B, Dursun $H$, Kalyon TA: Congenital significance of congenital lumbosacral malformations in young male population with prolonged low back pain. Spine 30:E210-E213, 2005

25. Tian NF, Huang QS, Zhou P, Zhou Y, Wu RK, Lou Y, Xu HZ: Pedicle screw insertion accuracy with different assisted methods: A systematic review and meta-analysis of comparative studies. Eur Spine J 20:846-859, 2011

26. Tow BP, Yue WM, Srivastava A, Lai JM, Guo CM, Peng BC, Chen JL, Yew AK, Seng C, Tan SB: Does navigation improve accuracy of placement of pedicle screws in single level lumbar degenerative spondylolisthesis? A comparison between freehand and 3D O-Arm navigation techniques. J Spinal Disord Tech 28(8):E472-477, 2015

27. Ughwanogho E, Patel NM, Baldwin KD, Sampson NR, Flynn JM: Computed tomography-guided navigation of thoracic pedicle screws for adolescent idiopathic scoliosis results in more accurate placement and less screw removal. Spine 37:E473-478, 2012

28. Van de Kelft E, Costa F, Van der Planken D, Schils F: A prospective multicenter registry on the accuracy of pedicle screw placement in the thoracic, lumbar, and sacral levels with the use of the O-arm imaging system and Stealth Station Navigation. Spine 37:E1580-1587, 2012

29. Zausinger S, Scheder B, Uhl E, Heigl T, Morhard D, Tonn JC: Intraoperative computed tomography with integrated navigation system in spinal stabilizations. Spine 34:29192926, 2009 